\title{
Association between consanguineous marriage and child nutritional outcomes among currently married women in Pakistan
}

\author{
Bal Govind Chauhan ${ }^{\mathrm{a}, *}$, Diwakar Yadav ${ }^{\mathrm{b}}$, Suresh Jungari ${ }^{\mathrm{c}}$ \\ ${ }^{a}$ Gokhale Institute of Politics \& Economics, Pune, 411004, India \\ ${ }^{\mathrm{b}}$ State Institute of Health and Family Welfare, Uttar Pradesh, India \\ ${ }^{\mathrm{c}}$ Savitribai Phule Pune University, Pune, Maharashtra, India
}

\section{A R T I C L E I N F O}

\section{Keywords:}

Consanguineous marriage

Child nutrition

Child development

\begin{abstract}
A B S T R A C T
Introduction: This study examines the association between blood related marriage and children nutritional health outcomes among currently married women.

Methods: Using the cross-sectional third round of Pakistan Demographic Health Survey conducted among 11,763 currently married women in 2012-13. The methods of analyses included bi-variate and logistic regression models.

Results: Nearly two-thirds of the CMW reported blood related marriage also known as consanguineous. Among consanguineous marriages (66\% of the sample), $71 \%$ are in Sindh region followed by Baluchistan $(70 \%)$ and Punjab (65\%) in Pakistan and it ranges from 72 to $78 \%$ among the socioeconomically disadvantageous groups and in rural (71\%) area. Multivariate results shows that the risk of child stunting (UOR $=1.52, \mathrm{CI}=1.31-1.67$; $\mathrm{AOR}=1.24, \quad \mathrm{CI}=1.02-1.51) \quad$ and $\quad$ child $\quad$ underweight $\quad(\mathrm{UOR}=1.59, \quad \mathrm{CI}=1.34-1.89 ; \quad \mathrm{AOR}=1.31$, $\mathrm{CI}=1.04-1.63$ ) are higher among consanguineous marriage than non-consanguineous marriage.

Conclusion: The findings suggest that there is a relationship between consanguineous marriage and under nutrition children including stunting and underweight, even after controlling for other background characteristics of the CMW. Child health interventions for CMW need to provide tailored information on consanguineous marriages related awareness and programme.
\end{abstract}

\section{Introduction}

Around the world, consanguineous marriages (CM) have been practiced by many societies from ancient time. Consanguinity, defined as the marriage or unions between individuals of the same blood, is widely practiced in countries of Asia and Africa especially in societies where Islam religion prevails. The most common form of CM is between first cousins from both mother and father. Although, different form of $\mathrm{CM}$ practicing from cross-cousin to more distant relations and their practice varies by community to community and culture to culture. ${ }^{1}$ Consanguinity is a cultural practice in many countries, and around $10.4 \%$ of the population is married to biological or blood relatives globally. ${ }^{2}$

The prevalence of CM throughout the world is estimated to be approximately $20 \%$, and this rate varies from $20 \%$ to $60 \%$ in North Africa, the Middle East and Western Asia. ${ }^{3}$ In particular, family-based closerelation CM level is $32-34 \%$ in Yemen, $29-33 \%$ in Iraq, $25-30 \%$ in Afghanistan, 14-24\% in Egypt, 7-52\% in South India, 44-49\% in Sudan and $17-38 \%$ in Pakistan, respectively. ${ }^{3}$ Study indicates that $50 \%$ of marriages in urban areas of Pakistan are between blood relatives, with $80 \%$ of these being between first cousins. Additionally, malnourished children are higher among consanguineous parents compare to nonconsanguineous.

Women in consanguineous unions have commonly been reported in rural areas and among communities of low socioeconomic status. Consanguinity increases the prevalence of rare genetic congenital anomalies and nearly doubles the risk of neonatal and childhood Mortality, mental disorder and other anomalies in first cousin unions. ${ }^{7}$ Further, measure the effect of $\mathrm{CM}$ on health and disease, numerous scientific work has shown that consanguinity increases the death of infants before, during or immediately after birth. ${ }^{2,8,9}$

Using ecological study data from 63 countries, raising that offsprings from CM experience higher morbidity and mortality. ${ }^{10}$ Furthermore, the risk of congenital heart diseases is significantly high among children with parental consanguinity compared to non-consanguinity parents. ${ }^{11}$ Children born within the consanguineous unions,

\footnotetext{
* Corresponding author.

E-mail addresses: govind.iips@gmail.com (B.G. Chauhan), yadavdiwakar7@gmail.com (D. Yadav), sureshjungari28@gmail.com (S. Jungari).
} 
Table 1

Sample distribution of currently married women by selected background characteristics, Pakistan, 2012-13.

\begin{tabular}{|c|c|c|c|c|c|}
\hline \multirow[t]{2}{*}{ Background characteristics } & \multirow[t]{2}{*}{ Percent $(\mathrm{N})$} & \multicolumn{2}{|c|}{ Consanguineous marriage } & \multicolumn{2}{|c|}{ Test of association } \\
\hline & & Yes & No & Chi square & $\mathrm{P}$ value \\
\hline Sample size & 11763 & 7469 & 4286 & & \\
\hline Total \% & 100 & 66.0 & 34.0 & & \\
\hline \multicolumn{6}{|c|}{ Socio-economic and demographic factors } \\
\hline Women age group (in years) & & & & 6.2 & 0.044 \\
\hline Mean (SD) & $29.4(6.1)$ & $29.2(6.1)$ & $29.9(6.0)$ & & \\
\hline $16-20$ & $2.2(286)$ & 2.3 & 2.2 & & \\
\hline $20-29$ & $51.9(6014)$ & 53.4 & 49.1 & & \\
\hline $30-49$ & $45.9(5463)$ & 44.4 & 48.7 & & \\
\hline Birth order & & & & 5.9 & 0.051 \\
\hline 1st Birth order & $23.0(2640)$ & 22.3 & 24.3 & & \\
\hline 2-3 Birth Order & 36.7 (4239) & 36.6 & 36.9 & & \\
\hline 4 and above & $40.3(4884)$ & 41.1 & 38.8 & & \\
\hline Sex of the child & & & & 0.8 & 0.346 \\
\hline Male & $51.0(5989)$ & 51.5 & 50.1 & & \\
\hline Female & $49.0(5774)$ & 48.5 & 49.9 & & \\
\hline Number of living children & & & & 1.9 & 0.380 \\
\hline 0 or 1 & 14.8 (1697) & 14.9 & 14.7 & & \\
\hline 2-3 child & 43.1 (4978) & 42.5 & 44.2 & & \\
\hline 4 and above & $42.1(5088)$ & 42.6 & 41.1 & & \\
\hline Place of residence & & & & 208.9 & 0.000 \\
\hline Urban & $29.1(4970)$ & 23.8 & 39.4 & & \\
\hline Rural & 70.9 (6793) & 76.2 & 60.6 & & \\
\hline Women education level & & & & 185.4 & 0.000 \\
\hline No education & $57.2(6722)$ & 61.7 & 48.5 & & \\
\hline Primary & $17.0(1687)$ & 17.4 & 16.3 & & \\
\hline Secondary & $17.6(2077)$ & 15.1 & 22.7 & & \\
\hline Higher & $8.1(1277)$ & 5.8 & 12.5 & & \\
\hline Husband education level & & & & 28.6 & 0.000 \\
\hline No education & 34.1 (3798) & 34.6 & 32.9 & & \\
\hline Primary & $17.2(1667)$ & 17.9 & 15.8 & & \\
\hline Secondary & 33.4 (3786) & 33.3 & 33.8 & & \\
\hline Higher & $15.3(2474)$ & 14.2 & 17.4 & & \\
\hline Women working status & & & & 101.5 & 0.000 \\
\hline No & 74.2 (9483) & 71.1 & 80.4 & & \\
\hline Yes & $25.8(2233)$ & 28.9 & 19.6 & & \\
\hline Wealth quintile & & & & 169.1 & 0.000 \\
\hline Poorest & $23.9(2758)$ & 28.2 & 15.7 & & \\
\hline Poorer & 21.2 (2359) & 23.2 & 17.3 & & \\
\hline Middle & $19.6(2270)$ & 19.3 & 20.1 & & \\
\hline Richer & 19.6 (2196) & 16.4 & 25.9 & & \\
\hline Richest & $15.7(2180)$ & 12.9 & 21.0 & & \\
\hline Media exposure & & & & 22.2 & 0.000 \\
\hline No & $54.3(6268)$ & 56.9 & 49.2 & & \\
\hline Yes & $45.7(5456)$ & 43.0 & 50.8 & & \\
\hline Geographic region & & & & 133.0 & 0.000 \\
\hline Punjab & $57.3(3266)$ & 56.4 & 58.9 & & \\
\hline Sindh & $22.9(2523)$ & 24.7 & 19.3 & & \\
\hline Khyber Pakhtunkhwa & $13.8(2270)$ & 12.7 & 16.0 & & \\
\hline Baluchistan & $4.9(1902)$ & 5.2 & 4.3 & & \\
\hline Gilgit Baltistan and Islamabad & $1.1(1802)$ & 0.9 & 1.5 & & \\
\hline \multicolumn{6}{|l|}{ Environmental factors } \\
\hline Household having toilet facility & & & & 85.8 & 0.000 \\
\hline No & $38.3(4217)$ & 43.0 & 29.0 & & \\
\hline Yes & 61.7 (7089) & 56.9 & 70.9 & & \\
\hline Source of water facility & & & & 0.0 & 0.938 \\
\hline Unsafe & $20.2(1824)$ & 20.6 & 19.5 & & \\
\hline Safe & $79.8(6696)$ & 79.4 & 80.5 & & \\
\hline
\end{tabular}

Note: Cases will not be same due to missing values; all values are un-waited.

more likely rate of stillbirths, congenital malformations, low birth weight and head circumference. ${ }^{12}$

Consanguinity noted as the most significant cause of genetically related mortality in developing countries. Couples who married in their blood relation are more likely to experience the death of an off-spring compared to those not related by blood. ${ }^{13}$ It also demonstrated that a threefold increase in post-neonatal mortality and childhood morbidity in the off-springs of couples having CM. It was also found that $60 \%$ of the mortality and morbidity of children could be eliminated if these marriages are stopped in Pakistan. In rural Sindh, consanguinity was identified as a risk factor for underweight of the children. Children who were underweight were 1.5 times more likely to have consanguineous parents then normal children. ${ }^{4}$ In India, linkage found between the genetic effect of consanguinity and newborn mortality among close CM after controlling for the non-genetic determinants. ${ }^{14}$ In Pakistan, new born in consanguineous unions had higher mortality rates in Pakistan. However, a study did not found any significant differential in the consanguineous union and no-consanguineous samples with respect to pre or post-natal mortalities and child morbidities. ${ }^{15}$ In contrast, in Qatar, a study of 1,515 women found $54 \%$ consanguineous marriages 
Table 2

Factors associated with consanguineous marriage among currently married women in Pakistan.

\begin{tabular}{|c|c|c|}
\hline \multirow[t]{2}{*}{ Characteristics } & \multicolumn{2}{|c|}{ Consanguineous marriage (OR; 95\% CI) } \\
\hline & Unadjusted & Adjusted \\
\hline \multicolumn{3}{|l|}{ Women age group (in years) } \\
\hline $16-20^{\oplus}$ & 1.00 & 1.00 \\
\hline $20-29$ & $0.93(0.73-1.19)$ & $0.91(0.67-1.23)$ \\
\hline $30-49$ & $0.85(0.66-1.09)$ & $0.79(0.58-1.09)$ \\
\hline \multicolumn{3}{|l|}{ Birth order } \\
\hline 1st Birth order ${ }^{\circledast}$ & 1.00 & 1.00 \\
\hline 2-3 Birth Order & $1.03(0.93-1.14)$ & $1.03(0.88-1.19)$ \\
\hline 4 and above & $1.12(1.01-1.23)^{* *}$ & $1.13(0.90-1.41)$ \\
\hline \multicolumn{3}{|l|}{ Place of residence } \\
\hline Urban $^{\circledast}$ & 1.00 & 1.00 \\
\hline Rural & $1.75(1.62-1.88)^{* * *}$ & $1.42(1.27-1.57)^{* * *}$ \\
\hline \multicolumn{3}{|l|}{ Women education level } \\
\hline No Education ${ }^{\circledast}$ & 1.00 & 1.00 \\
\hline Primary & $0.92(0.82-1.03)^{*}$ & $1.04(0.89-1.19)$ \\
\hline Secondary & $0.66(0.59-0.73)^{* * *}$ & $0.83(0.72-0.96)^{* * *}$ \\
\hline Higher & $0.47(0.42-0.53)^{* * *}$ & $0.59(0.49-0.71)^{* * *}$ \\
\hline \multicolumn{3}{|l|}{ Husband education level } \\
\hline No education ${ }^{\circledast}$ & 1.00 & 1.00 \\
\hline Primary & $0.99(0.88-1.12)$ & $1.17(1.01-1.36)^{* *}$ \\
\hline Secondary & $0.93(0.85-1.02)^{*}$ & $1.33(1.17-1.51)^{* * *}$ \\
\hline Higher & $0.76(0.68-0.85)^{* * *}$ & $1.36(1.17-1.59)^{* * *}$ \\
\hline \multicolumn{3}{|l|}{ Respondent working status } \\
\hline $\mathrm{No}^{\circledast}$ & 1.00 & 1.00 \\
\hline Yes & $1.68(1.52-1.86)^{* * *}$ & $1.42(1.23-1.62)^{* * *}$ \\
\hline \multicolumn{3}{|l|}{ Wealth quintile } \\
\hline Poorest ${ }^{\oplus}$ & 1.00 & 1.00 \\
\hline Poorer & $0.88(0.78-0.99)^{* *}$ & $0.86(0.73-1.01)^{* *}$ \\
\hline Middle & $0.72(0.64-0.81)^{* * *}$ & $0.80(0.66-0.97)^{* *}$ \\
\hline Richer & $0.58(0.52-0.66)^{* * *}$ & $0.69(0.56-0.85)^{* * *}$ \\
\hline Richest & $0.51(0.45-0.57)^{* * *}$ & $0.75(0.60-0.95)^{* * *}$ \\
\hline \multicolumn{3}{|l|}{ Media exposure } \\
\hline $\mathrm{No}^{\circledast}$ & 1.00 & 1.00 \\
\hline Yes & $0.83(0.77-0.90)^{* * *}$ & $1.14(1.03-1.27)^{* * *}$ \\
\hline \multicolumn{3}{|l|}{ Geographic region } \\
\hline Punjab $^{\circledast}$ & 1.00 & 1.00 \\
\hline Sindh & $1.37(1.23-1.53)^{* * *}$ & $1.10(0.94-1.28)$ \\
\hline Khyber Pakhtunkhwa & $0.90(0.81-1.01)^{* *}$ & $0.98(0.85-1.13)$ \\
\hline Balochistan & $1.27(1.13-1.44)^{* * *}$ & $1.32(1.13-1.54)^{* * *}$ \\
\hline Gilgit Baltistan and Islamabad & $0.72(0.63-0.80)^{* * *}$ & $0.76(0.65-0.88)^{* * *}$ \\
\hline \multicolumn{3}{|l|}{ Hygienic toilet facility } \\
\hline $\mathrm{No}^{\oplus}$ & 1.00 & 1.00 \\
\hline Yes & $0.68(0.63-0.74)^{* * *}$ & $1.09(0.95-1.24)$ \\
\hline
\end{tabular}

${ }^{\circledR}$ - Reference; OR- Odds ratio; CI- Confidence Interval.

and the most common form of that was the marriage between first cousins. Inborn, children of these couples had a significantly higher rate of asthma, intellectual disability, epilepsy, and diabetes compared with children of non-consanguineous couples. ${ }^{16}$

In Pakistan, paucity of population based studies on understanding of the consanguineous marriage and its effect on children nutritional status. Earlier studies found that women married to their blood relatives experienced a greater amount of pregnancy loss, still birth and infant and childhood mortality as compared to those women married to their distant relatives or non-relatives. ${ }^{17,18}$ Studies from Arabs countries related to the effect of consanguinity on anthropometric measurements such as birth weight gave different results. Although, studies from Jordan $^{19}$ found a significant reduction in child birth weight with consanguinity of the parents. Little is known about the possible relationship between parental consanguinity and children nutritional status, is yet to address. In this backdrop, the present study aims to examine the prevalence, correlates of parental consanguinity and its effect on children nutritional status in Pakistan.

\section{Materials and methods}

\subsection{Data}

The data for the study comes from third wave of Pakistan Demographic Health Survey (PDHS) conducted during the period 2012-13(National Institute of Population Studies - NIPS/Pakistan \& ICF International, 2013; NIPS, 2013). A total of 14,569 ever-married women age 15-49 were identified in the 12,943 households for the interview. Of the eligible women, 13,558 were successfully interviewed, yielding a response rate of $93 \%$. As our study is based on children nutritional status information, therefore kids file have been used for the analysis. A total 11,773 women have been identified for the analysis. These are those women who have at least one child at the time of survey. This survey designed along with the similarity of the demographic and health surveys that had been conducted in many developing countries since the 1980s. PDHS conducted under the aegis of the Ministry of National Health Services, Regulations and Coordination and implemented by the National Institute of Population Studies (NIPS). The PDHS is designed to collect data on knowledge and practice of family planning, fertility levels, marriage, fertility preferences, child feeding practices, nutritional status of children and women, childhood mortality, maternal and child health, awareness and attitudes regarding HIV/AIDS, knowledge about other illnesses, and domestic violence.

\subsection{Predictor variable}

CMW between the ages of 15-49 years are asked specific questions about CM. The specific questions asked in this survey are "Is/was there a blood relationship between you and your husband? If Yes, What type of relationship (is/was) it?" (Options given for this question are "first cousin on father side', 'first cousin on mother side', 'second cousin', 'Others relationship'). For analysis purpose, we categorize blood relation with the husband as 'Yes' and those not reporting blood relation with the husband as 'No'.

\subsection{Response variable}

The anthropometric data on height-for-age (stunting) and weightfor-age (underweight) are our response variables. In survey, questions are asked to women concerning the nutritional status of their children by measuring the height and weight of all children under age five in selected households. According to WHO guidelines, a child with heightfor-age $\mathrm{z}$ score less than -2 standard deviations is classified as "stunted" and weight-for-age z-score of less than -2 standard deviations is classified as "underweight". Both response variables in this study are binary coded-such as children are Stunted coded 'Yes'and otherwise coded 'No' and underweight coded'Yes' and otherwise coded 'No'.

\subsection{Control variables}

Socio-economic and demographic characteristics such as the mother's current age, education level, birth order, husband education level, working status, household wealth quintiles, media exposure, type of residence, geographic region are included in this study. The mother's age categorized into below 20 years, $20-39$ years, and 30-49 years. The birth orders of children are categorized into 1st Birth order, 2-3 Birth order and 4 and above. The education level of mother's are classified into no education, primary, secondary and higher. The nation geography are categorize into Punjab, Sindh, Khyber Pakhtunkhwa, Balochistan, Gilgitbaltistan and Islamabad.

The household wealth quintile indicator is widely used as a proxy indicator for assessing the household economic status from demographic health surveys (Howe, Hargreaves, Gabrysch, \& Huttly, 2009; Vyas \& Kumaranayake, 2006). The PDHS collects a wide range of 
Table 3

Prevalence of stunted and underweight children by background characteristics and consanguinity in Pakistan, 2012-13.

\begin{tabular}{|c|c|c|c|c|c|c|}
\hline \multirow[t]{3}{*}{ Characteristics } & \multirow[t]{3}{*}{ Total } & & \multicolumn{2}{|c|}{ Consanguineous marriage } & \multicolumn{2}{|c|}{ Consanguineous marriage } \\
\hline & & & Yes & No & Yes & No \\
\hline & & & \multicolumn{2}{|c|}{ Child stunted } & \multicolumn{2}{|c|}{ Child underweight } \\
\hline Sample size & 3071 & & 937 & 448 & 575 & 246 \\
\hline Total \% & 100 & & 70.5 & 29.5 & 72.5 & 27.5 \\
\hline \multicolumn{7}{|c|}{ Women age group (in years) } \\
\hline $16-20$ & 72 & & 1.6 & 3.3 & 3.0 & 4.0 \\
\hline $20-29$ & 1551 & & 54.6 & 48.7 & 57.1 & 43.3 \\
\hline $30-39$ & 1448 & & 43.8 & 48.0 & 39.9 & 52.7 \\
\hline \multicolumn{7}{|l|}{ Birth order } \\
\hline 1st Birth order & 693 & & 21.6 & 20.6 & 21.2 & 21.4 \\
\hline 2-3 Birth Order & 1126 & & 34.3 & 39.2 & 40.4 & 34.4 \\
\hline 4 and above & 1252 & & 44.1 & 40.1 & 38.4 & 44.2 \\
\hline \multicolumn{7}{|l|}{ Sex of child } \\
\hline Male & 1558 & & 53.7 & 54.6 & 53.1 & 60.1 \\
\hline Female & 1513 & & 46.3 & 45.4 & 46.9 & 39.9 \\
\hline \multicolumn{7}{|l|}{ Living children } \\
\hline 0 or 1 child & 386 & & 11.4 & 13.2 & 13.9 & 10.2 \\
\hline $2-3$ children & 1336 & & 40.9 & 42.2 & 42.1 & 43.6 \\
\hline 4 and above children & 1349 & & 47.7 & 44.6 & 44.0 & 46.2 \\
\hline \multicolumn{7}{|l|}{ Place of residence } \\
\hline Urban & 1330 & & 22.5 & 33.4 & 21.1 & 35.5 \\
\hline Rural & 1741 & & 77.5 & 66.6 & 78.9 & 64.5 \\
\hline \multicolumn{7}{|l|}{ Women education level } \\
\hline No education & 1606 & & 71.6 & 55.5 & 74.9 & 57.2 \\
\hline Primary & 497 & & 16.5 & 21.5 & 14.8 & 20.7 \\
\hline Secondary & 626 & & 9.0 & 16.1 & 7.5 & 17.4 \\
\hline Higher & 342 & & 2.9 & 6.9 & 2.7 & 4.7 \\
\hline \multicolumn{7}{|l|}{ Husband education level } \\
\hline No education & 909 & & 39.4 & 37.4 & 37.1 & 39.3 \\
\hline Primary & 455 & & 20.5 & 21.5 & 21.4 & 22.9 \\
\hline Secondary & 1045 & & 27.3 & 26.9 & 29.3 & 28.4 \\
\hline Higher & 659 & & 12.8 & 14.1 & 12.2 & 9.5 \\
\hline \multicolumn{7}{|l|}{ Respondent work status } \\
\hline No & 2423 & & 65.4 & 74.9 & 65.2 & 75.6 \\
\hline Yes & 641 & & 34.6 & 25.1 & 34.8 & 24.4 \\
\hline \multicolumn{7}{|l|}{ Wealth quintile } \\
\hline Poorest & 634 & & 33.1 & 20.8 & 37.7 & 25.8 \\
\hline Poorer & 613 & & 26.1 & 22.8 & 24.1 & 19.3 \\
\hline Middle & 554 & & 17.3 & 15.4 & 16.8 & 14.2 \\
\hline Richer & 658 & & 17.0 & 27.3 & 14.2 & 27.6 \\
\hline Richest & 612 & & 6.6 & 13.6 & 7.1 & 13.1 \\
\hline \multicolumn{7}{|l|}{ Media exposure } \\
\hline No exposure & 1582 & & 63.1 & 57.6 & 63.5 & 58.0 \\
\hline Exposure & 1448 & & 36.9 & 42.4 & 36.5 & 42.0 \\
\hline \multicolumn{7}{|l|}{ Geographic region } \\
\hline Punjab & & 1018 & 55.1 & 57.7 & 54.0 & 56.2 \\
\hline Sindh & & 704 & 31.6 & 21.7 & 34.4 & 26.8 \\
\hline Khyber Pakhtunkhwa & & 541 & 8.5 & 14.5 & 7.9 & 13.8 \\
\hline Balochistan & & 292 & 4.1 & 4.7 & 3.3 & 2.2 \\
\hline Gilgit Baltistan and & & 516 & .6 & 1.3 & .4 & 1.1 \\
\hline Hygienic toilet facility & & & & & & \\
\hline No & & 968 & 45.8 & 34.2 & 47.1 & 36.9 \\
\hline Yes & & 1944 & 54.2 & 65.8 & 52.9 & 63.1 \\
\hline Source of water facility & & & & & & \\
\hline Unsafe & & 421 & 21.5 & 23.8 & 25.5 & 24.3 \\
\hline Safe & & 1676 & 78.5 & 76.2 & 74.5 & 75.7 \\
\hline
\end{tabular}

Note: case will not be same due to missing values; all values are un-waited.

information on 28 household ownership of assets such as consumable durables and housing conditions-used as a proxy for household economic status. In the PDHS III, the wealth quintiles was created using principal component analysis (PCA) on items related to possession of durable assets, access to utilities and infrastructure and housing characteristics. Individuals were ranked on the basis of their household scores and separated into quintiles, each representing $20 \%$ of the score, between poorest and richest. A detailed description on the methodology adopted to construct the wealth quintile is provided in the PDHS III report (National Institute of Population Studies - NIPS/Pakistan \& ICF
International, 2013).

The education levels of husband are classified into no education, primary, secondary, and higher. Media exposure measured by asking women about the frequency (daily; at least once in a week; less than once in a week; or not at all) with which they read a newspaper or magazine, watch television, or listen to the radio. The questions are (a) Do you read a newspaper or magazine daily, at least once a week, occasionally or not at all? (b) Do you listen to the radio daily, at least once a week, occasionally or not at all? (c) Do you watch television daily, at least once a week, occasionally or not at all? A composite indicator of 
Table 4

Unadjusted and adjusted effects [ORs, 95\%, CI] of consanguineous marriage and other characteristics on children nutritional health status among women, Pakistan, 2012-13.

\begin{tabular}{|c|c|c|c|c|}
\hline \multirow[t]{2}{*}{ Characteristics } & \multicolumn{2}{|c|}{ Stunting [OR $(95 \% \mathrm{CI})]$} & \multicolumn{2}{|c|}{ Underweight [OR (95\% CI)] } \\
\hline & Unadjusted & Adjusted & Unadjusted & Adjusted \\
\hline \multicolumn{5}{|l|}{ Consanguineous marriage } \\
\hline $\mathrm{No}^{\oplus}$ & 1.00 & 1.00 & 1.00 & 1.00 \\
\hline Yes & $1.52(1.31-1.67)^{* *}$ & $1.24(1.02-1.51)^{* *}$ & $1.59(1.34-1.89)^{* *}$ & $1.31(1.04-1.63)$ \\
\hline \multicolumn{5}{|l|}{ Women age group } \\
\hline$<20^{\oplus}$ & & 1.00 & & 1.00 \\
\hline $20-29$ & & $1.13(0.60-2.14)$ & & $0.82(0.41-1.65)$ \\
\hline $30-49$ & & $1.24(0.63-2.42)$ & & $0.78(0.37-1.64)$ \\
\hline \multicolumn{5}{|l|}{ Birth order } \\
\hline 1st Birth order ${ }^{\circledast}$ & & 1.00 & & 1.00 \\
\hline 2-3 Birth Order & & $1.04(0.76-1.44)$ & & $1.11(0.77-1.59)$ \\
\hline 4 and above & & $0.73(0.45-1.17)$ & & $0.85(0.49-1.44)$ \\
\hline \multicolumn{5}{|l|}{ Geographic region } \\
\hline Punjab ${ }^{\circledast}$ & & 1.00 & & 1.00 \\
\hline Sindh & & $1.917(1.42-2.59)^{* * *}$ & & $2.09(1.50-2.91)$ \\
\hline Khyber Pakhtunkhwa & & $1.01(0.76-1.34)$ & & $1.01(0.73-1.40)$ \\
\hline Balochistan & & $6.292(4.26-9.28)^{* * *}$ & & $1.68(1.15-2.48)$ \\
\hline Gilgit Baltistan and Islamabad & & $0.96(0.72-1.30)$ & & $0.57(0.39-0.83)$ \\
\hline \multicolumn{5}{|l|}{ Place of residence } \\
\hline Urban $^{\oplus}$ & & 1.00 & & 1.00 \\
\hline Rural & & $0.81(0.64-1.02)^{*}$ & & $1.08(0.83-1.40)$ \\
\hline \multicolumn{5}{|l|}{ Mother education level } \\
\hline No Education ${ }^{\circledast}$ & & 1.00 & & 1.00 \\
\hline Primary & & $0.99(0.75-1.30)$ & & $0.82(0.59-1.11)$ \\
\hline Secondary & & $0.604(0.44-0.81)^{* * *}$ & & $0.47(0.33-0.67)$ \\
\hline Higher & & $0.58(0.38-0.88)^{* * *}$ & & $0.452(0.27-0.75)$ \\
\hline \multicolumn{5}{|l|}{ Husband education level } \\
\hline No education ${ }^{\circledast}$ & & 1.00 & & \\
\hline Primary & & $0.97(0.72-1.33)$ & & $1.05(0.75-1.47)$ \\
\hline Secondary & & $0.89(0.68-1.15)$ & & $1.010(0.76-1.34)$ \\
\hline Higher & & $1.02(0.74-1.41)$ & & $0.83(0.57-1.20)$ \\
\hline \multicolumn{5}{|l|}{ Wealth quintile } \\
\hline Poorest $^{\oplus}$ & & 1.00 & & \\
\hline Poorer & & $1.07(0.75-1.53)$ & & $1.35(0.92-1.97)$ \\
\hline Middle & & $0.84(0.56-1.26)$ & & $1.01(0.64-1.57)$ \\
\hline Richer & & $0.75(0.48-1.18)$ & & $1.01(0.62-1.64)$ \\
\hline Richest & & $0.39(0.24-0.65)^{* * *}$ & & $0.84(0.48-1.45)$ \\
\hline \multicolumn{5}{|l|}{ Number of living children } \\
\hline 0 or $1^{\oplus}$ & & 1.00 & & 1.00 \\
\hline $2-3$ child & & $0.95(0.65-1.39)$ & & $0.91(0.59-1.39)$ \\
\hline 4 and above & & $1.42(0.84-2.38)$ & & $1.12(0.63-1.98)$ \\
\hline \multicolumn{5}{|l|}{ Respondent currently working } \\
\hline $\mathrm{No}^{\oplus}$ & & 1.00 & & 1.00 \\
\hline Yes & & $1.16(0.87-1.54)$ & & $1.11(0.82-1.50)$ \\
\hline \multicolumn{5}{|l|}{ Media exposure } \\
\hline $\mathrm{No}^{\oplus}$ & & 1.00 & & 1.00 \\
\hline Yes & & $0.83(0.66-1.04)$ & & $0.84(0.65-1.08)$ \\
\hline \multicolumn{5}{|l|}{ Hygienic toilet facility } \\
\hline $\mathrm{No}^{\circledast}$ & & 1.00 & & 1.00 \\
\hline Yes & & $1.07(0.81-1.41)$ & & $1.23(0.90-1.67)$ \\
\hline \multicolumn{5}{|l|}{ Source of water facility } \\
\hline Unsafe ${ }^{\circledR}$ & & 1.00 & & 1.00 \\
\hline Safe & & $0.98(0.76-1.27)$ & & $0.95(0.72-1.26)$ \\
\hline
\end{tabular}

${ }^{\circledR}$ is the reference category; **p $<0.05$.

OR- Odds Ratio; CI- Confidence Interval.

the respondent's exposure to media is created: Individuals who read a newspaper or magazine, watch television, or listen to the radio daily or at least once a week are considered to be exposed to any media and coded as 'Yes'; otherwise not exposed to media coded as 'No'.

Those household using-flush to piped sewer system, flush to septic tank and flush to pit latrine consider as hygienic toilet facility coded as 'Yes' and otherwise not hygienic toilet facility coded as 'No'. Similarly, if household using water from piped into dwelling, piped to yard/plot, tube well or borehole, protected well, protected spring, tanker truck, cart with small tank and bottle water consider as source of water facility coded as 'safe' and otherwise coded as 'unsafe'. The geographical region are classified to five geographical categories Punjab, Sindh, Khyber Pakhtunkhwa, Balochistan and Gilgit Baltistan and Islamabad (both
Gilgit Baltistan and Islamabad) because disaggregation of Gilgit Baltistan and Islamabadhas little statistical significance given their small numbers.

\subsection{Analysis}

Bivariate and multivariate techniques is used for data analysis. From the bivariate analysis, cross-tabulation perform, and Chi-square test is used to test of significance. In first stage, examine the association and variation in occurrence of consanguineous marriage by socioeconomic and demographic characteristics of women. In the second stage, the trivariate estimates are calculated with children's stunting and underweight as an outcome variable and consanguineous marriage and other 
socioeconomic and demographic variables as independent variables. In the third stage, as our response variable-children nutritional status is dichotomous, binary logistic regression is used to see the adjusted effect of blood relation with the husband and other control factors on the children nutritional status.

\section{Results}

\subsection{Prevalence and pattern of consanguineous marriage among currently married women}

Table 1 represents the distribution of the currently married women during the five years preceding the survey date, by selected background characteristics. Of the 11,763 CMW who had participated and interviewed in survey, every second of the currently married women are aged 20-29 years. The mean age of the women is 29.4 years (SD: 6.1). The majority of respondents are not educated (57\%), not working (74\%) and belongs to poorest and poorer households (45\%). About $71 \% \mathrm{CMW}$ resides in rural place of residence. The Punjab (57\%) region has highest proportion of CMW followed by Sindh (23\%) and Khyber Pakhtunkhwa (14\%), Baluchistan (5\%) and Gilgit Balistan and Islamabad (1\%), respectively. More than three-fifth and four-fifth households are having hygienic toilet facility and safe source of water facility, respectively.

In bivariate analyses, about $66 \%$ of currently married women are married within the blood relation and with selected characteristics are varied in Table 1. Among consanguineous union, highest proportion of first cousin on father's side union (41\%), followed by first cousin on mother's side (33\%) and other relationship (27\%), respectively (data not presented in Table). Among cross-cousin marriages, about every one out of two (53\%) are aged $20-24$ years, $62 \%$ are not educated, $35 \%$ of women's husband are not educated, nearly three-fourth women are not working, $50 \%$ are residing in poorest and poorer household according to wealth quintiles. More than three-fourth (76\%) women are belongs to rural place of residence. Punjab (56\%) region has highest proportion of women in consanguineous unions followed by Sindh (25\%) and Khyber Pakhtunkhwa (13\%), respectively.

\subsection{Predictors of consanguineous marriage among CMW}

The results in Table 2 shows that occurrence of $\mathrm{CM}$ are more likely from rural place of residence ( $\mathrm{AOR}=1.42,95 \%, \mathrm{CI}=1.27-1.57$ ), husband's higher level of education (AOR $=1.36 .95 \%$, $\mathrm{CI}=1.17-1.59)$, working (AOR $=1.42,95 \%, \mathrm{CI}=1.23-1.62)$, exposed to media (AOR $=1.14,95 \%, \mathrm{CI}=1.03-1.27$ ) and Baluchistan region $(\mathrm{AOR}=1.32,95 \%, \mathrm{CI}=1.13-1.54)$. However, they are less likely to have higher level of education (AOR $=0.59,95 \%$, $\mathrm{CI}=0.49-0.71)$, richest household wealth quintiles $(\mathrm{AOR}=0.75$, $95 \%, \mathrm{CI}=0.60-0.95)$ and Gilgit Baltistan and Islamabad region (AOR $=0.78,95 \%, \mathrm{CI}=0.65-0.88$ ). There are no statistical significant association between $\mathrm{CM}$ and women's age.

\subsection{Prevalence of stunting and underweight children by background characteristic and consanguinity}

Table 3 presents the prevalence of stunted and underweight children by selected background characteristics and consanguinity. Results reveal that the prevalence of stunting (70\%) and underweight $(73 \%)$ children is high among women who got married to their blood relatives compared to their counterparts. Compared with non-consanguineous group, high prevalence of stunted children identified of women age group 20-29 years (49\% Vs 55\%), women have 4th child birth order ( $40 \%$ vs $44 \%$ ), rural place of residence ( $66 \%$ vs $78 \%$ ), not educated ( $56 \%$ vs $72 \%$ ), working women ( $25 \%$ vs $35 \%$ ), poorest household wealth quintiles (21\% vs $33 \%)$ and Sindh region $(22 \%$ vs $32 \%)$ among consanguineous marriage. A marginally high prevalence of stunted children's household having safe water facility among consanguineous marriage compared to non-consanguinity (79\% vs $76 \%)$.

Compared with non-consanguinity, high prevalence of underweight children identified of women age group 20-29 years (43\% Vs $57 \%$ ), women have 2 nd and $3^{\text {rd }}$ child birth order ( $34 \%$ vs $40 \%$ ), rural place of residence ( $64 \%$ vs $79 \%$ ), not educated ( $57 \%$ vs $75 \%$ ), working women ( $24 \%$ vs $35 \%$ ), poorest household wealth quintiles ( $26 \%$ vs $38 \%$ ) and Sindh region (27\% vs $34 \%$ ) among women who got married to their blood relatives. A marginally high prevalence of underweight children's household having no hygienic toilet facility among consanguineous marriage compared to non-consanguinity ( $37 \%$ vs $47 \%$ ).

\subsection{Effect of consanguineous marriage on children nutritional status}

Table 4 presents the unadjusted and adjusted effects of blood relation with the husband and selected characteristics on children stunting and underweight among women from binary logistic regression models. The unadjusted results show that women who have blood relation with the husband are 1.5 times more likely to have stunted children than without blood relation with husband. In the next model which adjusts for various socioeconomic demographic factors, the odds of having stunting children are higher for those who have blood relation with husband. Considering underweight children, the unadjusted model shows that consanguineous marriage women are 1.6 times more likely to have underweight children than non-consanguineous marriage, which remains not significant in the adjusted model ( $\mathrm{AOR}=1.31$, $95 \%, \mathrm{CI}=1.04-1.63)$. The logistic regression model indicates that consanguineous marriages are the crucial determinant of child nutritional status in Pakistan. Further, mother's age and education, place of residence, household assets based wealth quintile, media exposure, availability of hygienic toilet facility and source of drinking water is the important determinant of the child stunting and underweight.

\section{Discussion}

Numerous earlier studies at the micro as well macro level have focussed on the particular sector and social groups and described the prevalence of consanguineous marriages and its effects child health in Pakistan, yet limited study on assessing the effect of consanguineous marriages and children nutritional status has done. The current research is a comprehensive effort to investigate the consanguineous marriages and its effects with more recent national level data using reliable statistical methods to assess the prevalence and effect of consanguineous marriages on children nutritional status in Pakistan.

A large proportion of marriages (66\%) still happen between blood relative and among them a large proportion of children $(70 \%$ are stunted, and $73 \%$ are underweight) are malnourished in Pakistan. One of the main reason for the higher proportion of occurrence of consanguineous marriage in Pakistan may be parents continue to be the prime decision-makers for marriage of both son and daughter. Further, preferences for consanguineous marriage are socio-cultural rather than any perceived economic benefits, either in the form of consolidation of family property or smaller and less expensive dowries. In the rural setup, consanguinity is practiced even more, as it is thought to preserve social structure regarding ethnic and tribal affiliation. ${ }^{20}$ Educational status of women has one of the strongest influences on consanguineous marriage. Previous studies also have evidence that occurrence of consanguineous marriage decreases as women's education level increases. ${ }^{21,22}$

The consanguineous marriage frequency of women who are not literate is three times greater than that of women who graduated from university or above. Household economic status is also is a major factor in the occurrence of consanguineous marriage between blood relations as observed in the study. In Turkey, found that the frequency of consanguineous marriage was lowest for women with a high-income level. ${ }^{23}$ It is generally thought that giving women a greater chance to 
participate in the labour market will increase their autonomy around their marriage decisions.

The present study found that the risk of stunting and underweight in children is higher among those have married in the blood relation than those who has not. Similarly, Sindh region study found that consanguinity is one of the most significant predictors, which increases the risk of underweight in the children. They found that couples who were first cousins were 1.5 times more likely to have an underweight child as compared to those couples who were not first cousins. ${ }^{4}$ Another study of Pakistan using the secondary data set found the similar findings. ${ }^{24}$ In Libya, parental consanguinity was a significant factor associated with stunting of the children in bivariate analysis in his study in Libya, but it disappeared in multivariate analysis indicating that it was a confounding variable. ${ }^{25}$ Consanguinity increase the risk of congenital anomalies and infant mortality and it also increase the risk of intrauterine growth retardation. ${ }^{26-28}$ All these consequences of consanguinity influence a child to poor growth afterwards.

\section{Conclusion}

The analysis presented here convincingly demonstrates that there is a significant association between the practice of marriage within blood relatives and children nutritional status in Pakistan. Children stunting and underweight, which are assessed in this study, show a greater prevalence among consanguineous parent compared to non-consanguineous parent. In a country like Pakistan, where more than twothirds of all marriages are still between blood relatives, the findings of this study assume an importance not only for socio-cultural reasons but also to understand the children nutrition health outcomes. Public educational campaigns based on scientific evidence could help the purpose of the study. However, it is important that the social and economic benefits of marriage to a close relative also be taken fully into consideration. Therefore, a national program should select strategies that have enough strength to dilute the cultural taboos linked with these social practices and educate the people on the health risks associated with consanguineous marriages.

\section{Acknowledgments}

All the authors are grateful to all anonymous reviewers for the constructive comments in improving the manuscript.

\section{Appendix A. Supplementary data}

Supplementary data to this article can be found online at https:// doi.org/10.1016/j.cegh.2019.04.003.

\section{Authors' contributions}

All authors have equally contributed to prepare the manuscript.

\section{Conflicts of interest}

Authors declare no known competing interest.

\section{References}

1. Yunis K, El Rafei R, Mumtaz G. International perspectives: consanguinity: perinatal outcomes and prevention-A view from the Middle East. NeoReviews. 2008 Feb 1;9(2):e59-65.

2. Bittles AH, Black ML. The impact of consanguinity on neonatal and infant health. Early Hum Dev. 2010 Nov 1;86(11):737-741.

3. Hamamy H, Antonarakis Se Fau - Cavalli-Sforza LL, Cavalli-Sforza Ll Fau - Temtamy S, et al. Consanguineous marriages, pearls and perils: Geneva international consanguinity workshop report. Genet Med. 2011;13(9):841-847 1530-0366 (Electronic)

4. Hasnain SF, Hashmi SK. Consanguinity among the risk factors for underweight in children under five: a study from rural Sindh. J Ayub Med Coll Abbottabad. 2009 Sep 1;21(3):111-116.

5. Hussain R. Community perceptions of reasons for preference for consanguineous marriages in Pakistan. J Biosoc Sci. 1999 Oct;31(4):449-461.

6. Koc I. Prevalence and sociodemographic correlates of consanguineous marriages in Turkey. J Biosoc Sci. 2008 Jan;40(1):137-148.

7. World Health Organization. World Health Organization. Management of Substance Abuse Unit. Global Status Report on Alcohol and Health World Health Organization; 20142014.

8. Khayat RG, Saxena PC. Consanguinity and its Effect on Fertility and Infant and Child Mortality in Egypt. InPopulation Association of America Annual Meeting; 2005.

9. Tadmouri GO, Nair P, Obeid T, Al Ali MT, Al Khaja N, Hamamy HA. Consanguinity and reproductive health among Arabs. Reprod Health. 2009 Dec;6(1):17.

10. Saadat M. Association between healthy life expectancy at birth and consanguineous marriages in 63 countries. J Biosoc Sci. 2011 Jul;43(4):475-480.

11. Ramegowda S, Ramachandra NB. Parental consanguinity increases congenital heart diseases in South India. Ann Hum Biol. 2006 Jan 1;33(5-6):519-528.

12. Kulkarni ML, Kurian M. Consanguinity and its effect on fetal growth and development: a south Indian study. J Med Genet. 1990 Jun 1;27(6):348-352.

13. Shah GH, Toney MB, Pitcher BL. Consanguinity and child mortality: the risk faced by families. Popul Res Pol Rev. 1998 Jun 1;17(3):275-283.

14. Banerjee SK, Roy TK. Parental consanguinity and offspring mortality: the search for possible linkage in the Indian context. Asia Pac Popul J. 2002 Mar 1;17(1):17-38.

15. Riaz HF, Mannan S, Malik S. Consanguinity and its socio-biological parameters in Rahim yar Khan district, Southern Punjab, Pakistan. J Health Popul Nutr. 2016 Dec;35(1):14.

16. Bener A, Hussain R. Consanguineous unions and child health in the State of Qatar. Paediatr Perinat Epidemiol. 2006 Sep;20(5):372-378.

17. Maghsoudlou S, Cnattingius S, Aarabi M, et al. Consanguineous marriage, prepregnancy maternal characteristics and stillbirth risk: a population-based casecontrol study. Acta Obstet Gynecol Scand. 2015 Oct 1;94(10):1095-1101.

18. Kuntla S, Goli S, Sekher TV, Doshi R. Consanguineous marriages and their effects on pregnancy outcomes in India. Int J Sociol Soc Policy. 2013 Jul 19:33(7/8):437-452.

19. Obeidat BR, Khader YS, Amarin ZO, Kassawneh M, Al Omari M. Consanguinity and adverse pregnancy outcomes: the north of Jordan experience. Matern Child Health J. 2010 Mar 1;14(2):283-289.

20. Hussain R. The effect of religious, cultural and social identity on population genetic structure among Muslims in Pakistan. Ann Hum Biol. 2005 Mar 1;32(2):145-153.

21. Bhasin P, Kapoor S. Impact of consanguinity on cardio-metabolic health and other diseases: findings from an Afro-Indian tribal community. Journal of community genetics. 2015 Apr 1;6(2):129-135.

22. Jabeen N, Malik S. Consanguinity and its sociodemographic differentials in Bhimber district, Azad Jammu and Kashmir, Pakistan. J Health Popul Nutr. 2014 Jun;32(2):301.

23. Akbayram S, Sari N, Akgün C, et al. The frequency of consanguineous marriage in eastern Turkey. Genet Couns. 2009 Jul 1;20(3):207.

24. Tariq J, Sajjad A, Zakar R, Zakar M, Fischer F. Factors associated with undernutrition in children under the age of two years: secondary data analysis based on the Pakistan demographic and health survey 2012-2013. Nutrients. 2018 Jun;10(6):676.

25. El Taguri A, Betilmal I, Mahmud SM, et al. Risk factors for stunting among underfives in Libya. Publ Health Nutr. 2009 Aug:12(8):1141-1149.

26. Hussain R, Bittles AH, Sullivan S. Consanguinity and early mortality in the Muslim populations of India and Pakistan. Am J Hum Biol. 2001;13:777-787 35.

27. Gustaven KH. Prevalence and aetiology of congenital birth defects, infant mortality and mental retardation in Lahore, Pakistan: a prospective cohort study. Acta Paediatr. 2005;94:769-774 36

28. al-Eissa YA, Ba'Aqeel HS, Haque KN, et al. Determinants of term intrauterine growth retardation: the Saudi experience. Am J Perinatol. 1995;12:278-281. 